This item was submitted to Loughborough's Research Repository by the author.

Items in Figshare are protected by copyright, with all rights reserved, unless otherwise indicated.

\title{
Comparative performance of in-line rotor-stators for deagglomeration processes
}

PLEASE CITE THE PUBLISHED VERSION

http://dx.doi.org/10.1016/j.ces.2016.09.023

PUBLISHER

(c) Elsevier

VERSION

AM (Accepted Manuscript)

\section{PUBLISHER STATEMENT}

This work is made available according to the conditions of the Creative Commons Attribution-NonCommercialNoDerivatives 4.0 International (CC BY-NC-ND 4.0) licence. Full details of this licence are available at: https://creativecommons.org/licenses/by-nc-nd/4.0/

\section{LICENCE}

CC BY-NC-ND 4.0

\section{REPOSITORY RECORD}

Ozcan-Taskin, Gul, Gustavo A. Padron, and Dominik Kubicki. 2016. "Comparative Performance of In-line Rotor-stators for Deagglomeration Processes". Loughborough University. https://hdl.handle.net/2134/22955. 


\title{
Comparative Performance of In-Line Rotor-Stators for Deagglomeration Processes
}

\author{
N. Gül Özcan-Taşkınn ${ }^{1}$, Gustavo A. Padron and Dominik Kubicki² \\ BHR Group, Cranfield, Bedfordshire MK43 0AJ UK \\ ${ }^{1}$ Present address: Loughborough University, School of Aeronautical, Automotive, Chemical and \\ Materials Engineering, Department of Chemical Engineering, Loughborough LE11 3TU, UK \\ corresponding author N.Ozcan-Taskin@lboro.ac.uk \\ ${ }^{2}$ Present address: The Engineering Design Centre, Warsaw, Poland
}

\begin{abstract}
In-line rotor-stators are used for a wide range of power intensive dispersion applications, including the breakup of immiscible liquid droplets or agglomerates. This study, performed within the DOMINO project at BHR Group, aimed at studying the performance of three different rotor-stator head designs for deagglomeration processes. A given test system, nanoscale silica particles-in-water, was used to identify the mechanism and kinetics of break-up and determine the smallest attainable size. Three rotorstator head designs used were the GPDH-SQHS and EMSC screens from Silverson and Ytron Z-Lab from Ytron. These in-line rotor-stators were used in the recirculation loop of a stirred tank with a total dispersion volume of 100 litres. Power input and residence time were varied by changing the rotor speed and dispersion flow rate. Breakup was found to occur through erosion regardless of the operating conditions or rotor-stator design. The smallest fragments obtained were aggregates, rather than primary particles, and these were of a mean diameter of 150-200 nm; also independent of the operating conditions or rotor-stator head design. With a given rotor-stator operated at a given flow rate, increasing the rotor speed and hence the power input increased the break up kinetics. For a given design at a given specific power input, whilst the break up rate per tank turnover decreased when the flow rate was increased, the total processing time could be reduced. There were differences in the volume of the mixer head and chamber volumes; in addition, a smaller flow rate range could be covered with the Ytron design. Comparison of the different designs was therefore not straightforward. It could however be shown that the rotor-stator designs with a high number and small size of holes and/or gaps have a faster break up rate.
\end{abstract}




\section{Highlights}

Three rotor-stator head designs were studied for the breakup of silica nanoparticle clusters:

- Mechanism of break up could be demonstrated to be erosion

- Dispersion fineness is limited by the aggregate size: 150-200 nm

- Kinetics of break up could be quantified; effect of operating conditions identified

- Effect of rotor-stator design (size and nb of holes and gap) on breakup discussed

Key words: in-line rotor-stators, deagglomeration, break up of nanoparticle clusters, dispersion, fragmentation, Aerosil 200V.

\section{INTRODUCTION}

Whilst the specific design of rotor-stators varies, high operating speeds (thousands of rpm) and flow through small openings (either small holes on the screens or gaps between the teeth and screens), which result in high levels of local energy dissipation rate and liquid velocities in the mixer head, are common features of these devices. They are therefore used in a range of power intensive applications for break up (of agglomerates or droplets), fast chemical reactions or foam generation. Zhang et al (2012) provide a review of applications along with flow and power characteristics of different batch and in-line rotor stators relating to rotor-stators.

The findings reported in this paper, performed within the DOMINO project run at BHR Group, aimed at investigating the deagglomeration of nanoparticle clusters in a liquid with different in-line rotor-stator heads. Other process devices used by previous researchers include the sawtooth impeller (Xie et al, 2007), batch rotor- stator (Xie et al, 2007; Pacek et al, 2007), high pressure devices (Xie et al, 2008; Sauter and Schuchmann, 2012), stirred bead mills (Kowalski et al, 2008, Schilde et al, 2011) and ultrasonicators (Sauter et al, 2006, 2008). Some of the studies included numerical modelling to develop both an understanding of the flows within process devices which are not accessible for measurements and also models describing the deagglomeration process (Baldyga et al, 2006, 2007, 2008, 2009). Different equipment suit different purposes for example, ultrasonic dispersers and batch rotor-stators are typically used 
at smaller scales, high pressure devices as secondary devices, i.e. once the dispersion has reached a certain degree of fineness so that the nozzles or channels will not be blocked, stirred bead mills for concentrated dispersions (above about 15\% w:w). Different in-line rotor-stator designs used in this study were the General Purpose Disintegrating Head (GPDH) with an outer Square Hole Screen (SQHS) or Emulsor Screen (EMSC) with the Silverson 150/250MS and Ytron Z-Lab. The study follows on from our previously reported work on the flow and power characteristics of these rotor-stator heads in a single phase system (Özcan-Taşkın et al., 2011). The characteristic power numbers, $\mathrm{Po}_{1}$ and $\mathrm{Po}_{2}$, from eqn. 1 are listed in Table 1

$$
P=P o_{1} \rho N^{3} D^{5}+P o_{2} \rho N^{2} D^{2} Q
$$

where $\mathrm{P}$ is the power $(\mathrm{W}), \rho$ the dispersion density $\left(\mathrm{kg} / \mathrm{m}^{3}\right), \mathrm{N}$ the rotor speed $\left(\mathrm{s}^{-1}\right), \mathrm{D}$ the rotor diameter $(\mathrm{m})$ and $\mathrm{Q}$ the volumetric flow rate through the rotor-stator $\left(\mathrm{m}^{3} / \mathrm{s}\right)$.

The Computational Fluid Dynamics (CFD) study revealed important features of the flow field generated by these rotor-stator heads. The zone of high energy dissipation rate was found to be located between the inner rotor and outer screen and within jets when using the GPDHSQHS and EMSC geometries, where breakage would be expected to occur. With the Ytron Z mixer, a more uniform distribution of the energy dissipation rate was noted throughout the whole chamber, which is only slightly larger than the rotor-stator head and pumping wheel assembly (Özcan-Taşkın et al, 2011). In addition, the fluid in the chamber appeared to be recirculated back into the mixer head when using the GPDH-SQHS and EMSC designs, with a higher circulation flow for the EMSC. This means that the dispersion can enter the zone of high energy dissipation rate many times during one pass through the GPDH-SQHS and EMSC. This effect was not observed in the Ytron $\mathrm{Z}$ geometry, which occupied practically the whole chamber, and recirculation was mainly within the teeth of the stator. 
Commercially available nanoparticle powders typically exist in the form of much larger clusters. Of these, aggregates are held together by sintering bridges and cannot be broken up, but agglomerates, which are held together by weaker bonds such as, van-der-Waals and hydrogen bonds, can be disintegrated further provided that the energy input in the processing environment is sufficiently high (Bałdyga et al, 2008a). The following expression proposed by Tang et al (2001) based on the earlier work by Rumpf (1962) has commonly been used to calculate the tensile strength of agglomerates, $\sigma_{T}$, (Baldyga et al, 2006; 2007a and 2007b; Özcan-Taşkın et al, 2009) which is related to the porosity of the clusters, $\varepsilon_{a}$ :

$$
\sigma_{T}=1.1 \frac{\left(1-\varepsilon_{a}\right)}{\varepsilon_{a}} \frac{F_{T}}{L_{a}^{2}}
$$

where $F_{T}$ is the force that holds the agglomerate together $\left(F_{T}=F_{A}+F_{R}\right)$ and $L_{a}$ the aggregate size. Based on the DLVO theory (Shaw, 1992) the forces within an agglomerate attributed to van der Waals forces $\left(F_{A}\right)$ and repulsive forces $\left(F_{R}\right)$ have been expressed as follows (Tang et al, 2001; Baldyga et al, 2006, 2007a and 2007b):

$$
\begin{gathered}
F_{A}=-\frac{H a R}{24 H^{2}} \\
F_{R}=\frac{16 \pi \chi R k_{B} T^{2}}{e^{2} z^{2} H}\left\{\frac{\exp \left[z e \psi_{0} /\left(2 k_{B} T\right)\right]-1}{\exp \left[z e \psi_{0} /\left(2 k_{B} T\right)\right]+1}\right\} \exp (-\kappa H)
\end{gathered}
$$

where $H a$ is the Hamaker constant; $R$ the radius and $H$ the distance between particles in a cluster; $\chi$ is the static permittivity; $k_{B}$ is the Boltzmann constant; $\psi_{0}$ the surface potential due to the surface charge on the particle (which can be taken as the zetapotential) and $\kappa$ is the reciprocal of the double layer thickness.

The average volume fraction of aggregates $(\bar{\varphi})$ and porosity $\left(\varepsilon_{\mathrm{a}}\right)$ in [2] are related as follows: 


$$
\bar{\varphi}=1-\varepsilon_{a}
$$

Whilst the aggregates are fused primary particles and hence remain intact, agglomerates can be broken up if the stresses in a processing environment are sufficiently high to overcome the tensile strength of agglomerates. Under turbulent conditions, turbulent stresses acting on agglomerates of a size $L_{i}$ result in breakage. Based on the early work by Kolmogorov (1949) and Hinze (1955), if $l \gg L_{i} \gg \lambda_{k}, l$ being macroscale of turbulence and $\lambda_{\mathrm{k}}$ Kolmogorov microscale, break up occurs through eddies in the inertial subrange of turbulence:

$$
\tau \propto \rho \varepsilon^{2 \backslash 3} L_{i}^{2 \backslash 3}
$$

$\varepsilon$ being the local energy dissipation rate per unit mass of liquid. If $L_{i}<\lambda_{k}$, break up occurs through viscous subrange eddies, as proposed by Baldyga and Bourne (1994):

$$
\tau \propto \mu\left(\frac{\varepsilon}{v}\right)^{1 / 2}=\rho v^{1 / 2} \varepsilon^{1 / 2}
$$

$v$ being the kinematic viscosity of the liquid.

The objective of this study has been to identify the mechanisms and kinetics of the breakup of clusters of nanoscale silica particles and the smallest attainable size using different design in-line rotor-stator heads. This study follows on from our previously reported results with these devices in single phase systems to determine the power and flow characteristics (Özcan-Taşkın et al., 2011) and on the effect of particle properties which was performed with one of the rotorstator heads but following a different experimental protocol (Özcan-Taşkın et al., 2009). The present work also included a brief CFD study under selected conditions. 


\section{EXPERIMENTAL- MATERIALS AND METHODS}

\subsection{Experimental set-up}

The experimental rig consisted of an in-line rotor-stator in the recirculation loop of a cylindrical, Perspex tank with a diameter of $T=0.61 \mathrm{~m}$ (Figure 1). The liquid volume was 100 1. The tank was equipped with a down-pumping pitched blade turbine (PBT) with blades inclined at $45^{\circ}$. The PBT had a diameter of $D=0.42 T$ and mounted at an off-bottom clearance of $C=T / 4$. It was operated at $155 \mathrm{rpm}$ to ensure homogeneity in the feed tank.

Two in-line devices used were the custom built Silverson 150/250MS and Ytron Z-Lab.

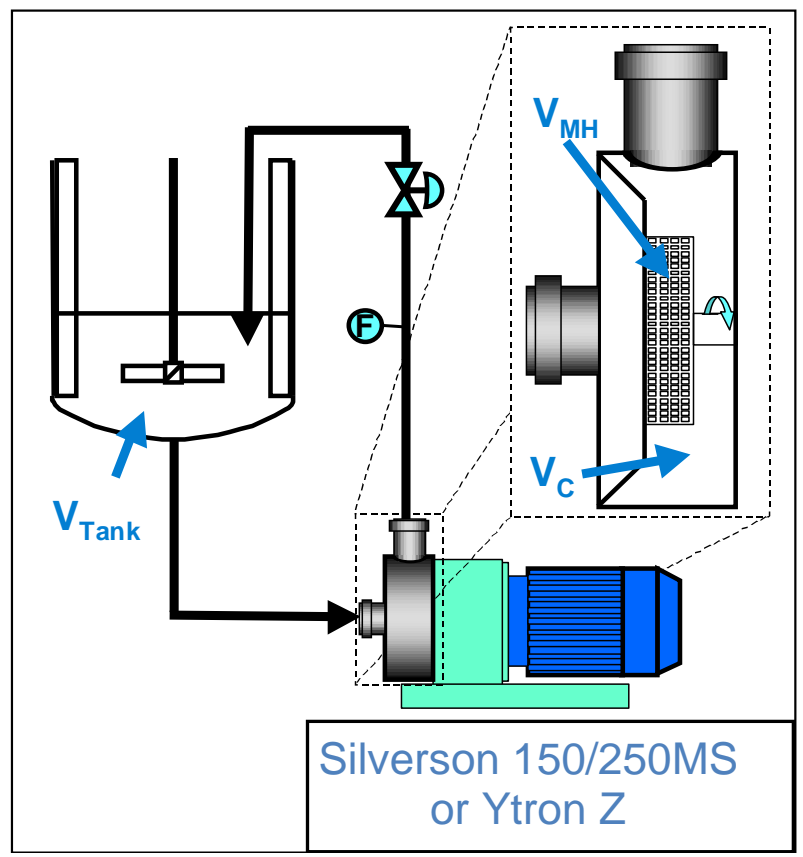

Figure 1 Experimental set up

\subsection{Rotor-stator geometries}

Of the three rotor-stator geometries, which are described below, the first two were used with the Silverson unit (Figure 2) and the last with the Ytron Z-Lab (Figure 3).

i. GPDH-SQHS is a two-stage rotor-stator design with the inner stator consisting of eight $10 \mathrm{~mm}$ diameter round holes (General Purpose Disintegrating Head) and the outer stator 
consisting of three rows of 2.4 x. $2.4 \mathrm{~mm}$ square holes (Square Hole High Shear Screen). The inner rotor consists of four blades and has a diameter of $38.2 \mathrm{~mm}$. The outer rotor is comprised of eight teeth with an external diameter of $63.5 \mathrm{~mm}$. The width of the rotor-stator gap in both stages is $0.15 \mathrm{~mm}$.

ii. EMSC is also a two stage stator with both stators consisting of 7 rows of $\sim 1 \mathrm{~mm}$ diameter round holes (Emulsor screens). The rotor is the same as that used with the GPDHSQHS. Silverson rotor-stator heads are shown in Figure 2.

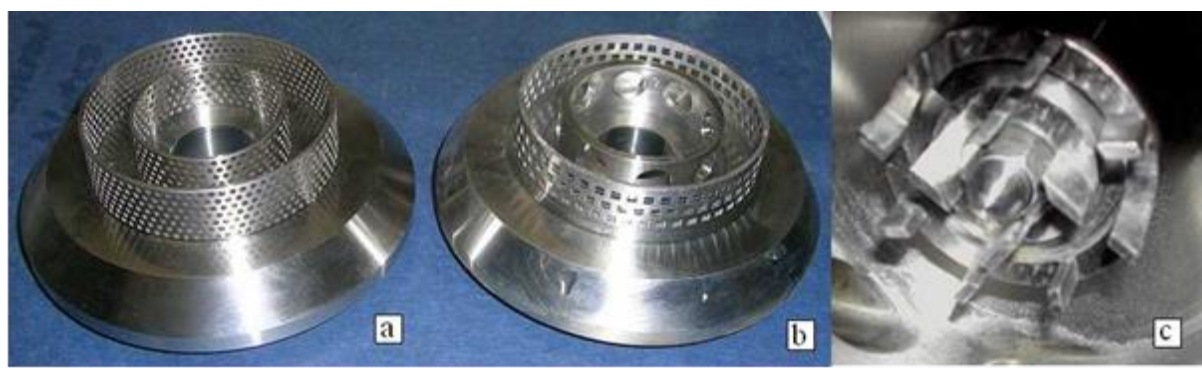

Figure 2 Silverson: (a) EMSC; (b) GPDH-SQHS (c) rotor

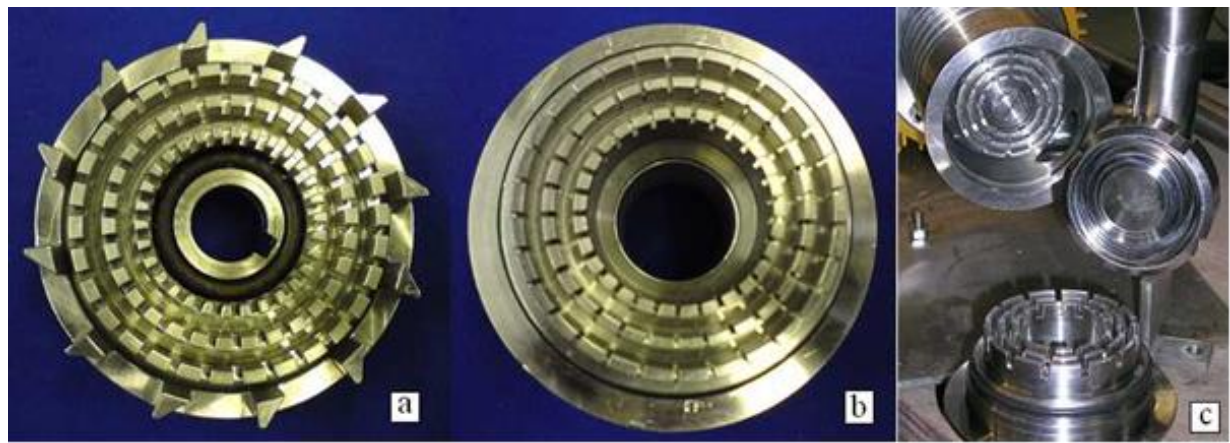

Figure 3 Ytron Z-Lab (a) rotor with pumping wheel; (b) stator; (c) mixing head

iii. Ytron $Z$ is from Ytron-Quadro. The rotor consists of three rows of 30 teeth separated by $1 \mathrm{~mm}$ gaps. The stator has three rows of 29 teeth, also separated by $1 \mathrm{~mm}$ gaps. The difference in the number of teeth between the rotor and the stator ensures that not all the gaps are aligned or closed simultaneously which would produce a pulsating flow. 
Whilst flow can be achieved during the operation of Silverson heads, either an external pump has to be used to achieve flow through Ytron Z-Lab or a "pumping wheel" needs to be fitted in the periphery of the rotor-stator. The latter was used in this study as shown in Figure 3. This pumping wheel consists of 12 triangular teeth and increases the effective diameter of the rotor to $70 \mathrm{~mm}$.

The differences in the rotor-stator heads can be seen in Figures 2 and 3. For the two Silverson heads, whilst the rotor is the same, which consists of two sets of blades, the stator GPDH-SQHS has fewer and larger holes compared to the EMSC. Ytron Z-Lab screen is significantly different from these as it consists of three sets of teeth with also a pumping wheel. In addition, the chamber and mixer head volumes ( $V_{C}$ and $V_{M H}$ in Figure 1) are different for the two devices. The volumes of the mixer head are closer for the two devices: $58 \mathrm{~cm}^{3}$ for the Silverson (based on the volume contained by the outer stator) and $49 \mathrm{~cm}^{3}$ for the Ytron (based on the volume contained by the external diameter of the rotor/pumping wheel). However, the sizes of the chambers where the mixing heads are housed are significantly different with Silverson having a volume almost 4 times larger than Ytron Z-Lab as detailed in Table 2. Therefore, two different flow rates were used with Ytron Z-Lab, one to match the residence time within the mixing heads and another to match the residence time within the chambers. Table 2 also summarises the different volumes and flow rates used for each mixer. 0.5 1/s was the highest flow rate attainable with this Ytron $\mathrm{Z}$ unit due to its lower pumping capacity compared to that of the Silverson (Özcan-Taskin et al, 2010).

Table 1 Power numbers for the three rotor-stator geometries (Özcan-Taşkın et al., 2011)

\begin{tabular}{|c|c|c|}
\cline { 2 - 3 } \multicolumn{1}{c|}{} & Po1 & Po2 \\
\hline GPDH-SQHS & 0.13 & 9.1 \\
\hline EMSC & 0.11 & 10.5 \\
\hline Ytron Z Lab & 0.18 & 10.6 \\
\hline
\end{tabular}


Table 2 Mixing head and chamber volumes of the Silverson and Ytron rotor-stators

\begin{tabular}{|c|c|c|c|c|}
\hline Rotor-Stator & $\begin{array}{c}\mathrm{V}_{\mathrm{C}} \\
\left(\mathrm{cm}^{3}\right)\end{array}$ & $\begin{array}{c}\mathrm{V}_{\mathrm{MH}} \\
\left(\mathrm{cm}^{3}\right)\end{array}$ & $\begin{array}{c}\mathrm{Q} \text { constant } \mathrm{t}_{\mathrm{res}} \text { in } \\
\text { Chamber }(\mathrm{l} / \mathrm{s})\end{array}$ & $\begin{array}{c}\mathrm{Q} \text { constant } \mathrm{t}_{\mathrm{res}} \\
\text { in MH }(\mathrm{l} / \mathrm{s})\end{array}$ \\
\hline $\begin{array}{c}\text { Silverson } \\
\text { 150/250MS }\end{array}$ & 603 & 58 & 0.6 & 0.6 \\
\hline Ytron Z-Lab & 160 & 49 & 0.16 & 0.5 \\
\hline
\end{tabular}

\subsection{Materials}

Silica particles, Aerosil@ 200V, supplied by Evonik Industries, were dispersed in distilled water. Aerosil ${ }^{\circledR} 200 \mathrm{~V}$ is a native, unmodified, densified fumed silica with a surface covered with silanol (Si-OH) groups to the tune of $\sim 2.5[\mathrm{SiOH}]$ groups $/ \mathrm{nm}^{2}$ (Degussa Technical Bulletin No 11, 2006). The silanol groups render the silica hydrophilic. The primary particle size of Aerosil $200 \mathrm{~V}$ is given as $12 \mathrm{~nm}$, the BET surface area $\sim 200 \mathrm{~m}^{2} / \mathrm{g}$ and the tapped density is approximately $120 \mathrm{~kg} \mathrm{~m}^{-3}$.

Silica, is widely used in a range of products to improve mechanical properties, for example to reinforce rubber, modify rheology of liquids, pastes and thermoplastics, improve surface effects of coatings as discussed in detail by Ferch (2005). Flame pyrolysis used in the manufacture of these particles is by far the most commonly used technique for the manufacture of commercial quantities of nanoparticles with annual production volumes of the order of several million metric tons (Kammler et al, 2001). This one-step process is favoured as it does not involve high volumes of liquids and high purity products can be obtained in short timescales. On the other hand, product particle characteristics are determined within a few milliseconds, which can be influenced by many process variables. In addition, proto-particles directly formed during the chemical reaction collide and coalesce at high flame temperatures. Collision, sticking and partial fusion of primary particles during manufacture result in the formation of aggregates held together by sintering bridges. While leaving the flame and cooling, the silica aggregates continue to collide, but their surfaces are now solid and agglomerates of aggregates are formed by physicochemical surface interactions (Barthel, 1995; Ulrich and 
Riehl, 1981). Consequently, the material on the market consists of aggregates and agglomerates of a broad size range well above the primary particle size.

\subsection{Experimental procedure and operating conditions}

Aerosil@ $200 \mathrm{~V}$ powder, pre-wetted in a 20-litre container in a fume cupboard, was introduced into the stirred tank, which contained the required amount of water to give the target final concentration of $1 \%$ wt. The dispersion was mixed for 10 minutes with the PBT at 155 rpm before the rotor-stator was started. This corresponds to $\mathrm{t}=0$ in the graphs presented. Experiments were run at a given rotor speed and flow rate which was adjusted by using the diaphragm valve downstream of the flow meter. The operating conditions summarised in Table 3 were chosen based on both the power characteristics of these devices to match the specific power input and also to obtain data at comparable residence time values in the rotor-stator head and mixing chamber.

Table 3 Operating Conditions

\begin{tabular}{|c|c|c|c|c|c|}
\hline & $\begin{array}{c}\mathbf{N} \\
\mathbf{r p m}\end{array}$ & $\begin{array}{c}\mathbf{Q} \\
\mathbf{l} / \mathbf{s}\end{array}$ & $\begin{array}{l}\mathrm{P} / \rho V \\
W / \mathrm{kg}\end{array}$ & $\begin{array}{c}\text { tres }^{\mathrm{C}} \\
\mathrm{S}\end{array}$ & $\begin{array}{c}\text { tres }^{\mathrm{MH}} \\
\mathrm{S}\end{array}$ \\
\hline \multirow{4}{*}{ GPDH-SQHS } & 3000 & 0.6 & 0.7 & 1 & 0.1 \\
\hline & 5000 & 0.6 & 2.3 & 1 & 0.1 \\
\hline & 7000 & 0.6 & 5.2 & 1 & 0.1 \\
\hline & 9000 & 0.6 & 9.6 & 1 & 0.1 \\
\hline \multirow{4}{*}{ EMSC } & 3375 & 0.6 & 1.0 & 1 & 0.1 \\
\hline & 4400 & 0.6 & 1.8 & 1 & 0.1 \\
\hline & 6150 & 0.6 & 3.9 & 1 & 0.1 \\
\hline & 7950 & 0.6 & 7.1 & 1 & 0.1 \\
\hline \multirow{4}{*}{ Ytron Z Lab } & 4510 & 0.16 & 1.8 & 1 & 0.3 \\
\hline & 7380 & 0.16 & 7.1 & 1 & 0.3 \\
\hline & 6610 & 0.5 & 7.4 & 0.3 & 0.1 \\
\hline & 7330 & 0.5 & 9.6 & 0.3 & 0.1 \\
\hline
\end{tabular}


Samples were taken from the sample valve after the rotor-stator during the course of the experiments. As the rate of change in particle size is known to be high initially, the time step between sampling was shorter at the start.

\subsection{Particle size measurements}

Particle size measurements were performed using the Beckman Coulter LS 230 particle size analyser. This instrument combines laser diffraction and Polarization Intensity Differential Scattering (PIDS) techniques to measure particles between $0.04-2000 \mu \mathrm{m}$.

A complex refractive index of $1.46+0.1 \mathrm{i}$ was applied in the particle size distribution calculations and the refractive index of water was taken as 1.333 .

\subsection{Quantitative analysis of fines generation rate}

For a bimodal particle size distribution of the dispersion entering the rotor-stator at time $t$, the following function can be used to describe the overall PSD, $q_{1}(t)$ :

$$
q_{1}(t)=F(t) q_{F}+(1-F(t)) q_{C}
$$

where $F(t)$ is the volume fraction of fine particles present in the distribution, $q_{F}$ is a function describing the PSD of the fine particles and $q_{C}$ is another function that describes the PSD of the coarse particles in the distribution. Similarly, the PSD of the dispersion leaving the rotor-stator at time $\mathrm{t}$ can be defined as:

$$
\mathrm{q}_{2}(\mathrm{t})=(1-\mathrm{Z}) \mathrm{q}_{1}(\mathrm{t})+\mathrm{Zq}_{\mathrm{F}}
$$


where $Z$ is the volume fraction of fines generated in a single pass through the rotor-stator. If a differential mass balance is performed over the total volume of dispersion $(V)$, the resulting differential equation is:

$$
V \frac{d q_{1}(t)}{d t}=Q\left[q_{2}(t)-q_{1}(t)\right]
$$

where $\mathrm{Q}$ is the volumetric flow rate through the rotor-stator. Equations [8], [9] and [10] can be combined to yield:

$$
\frac{d F}{d N_{T}}=Z(1-F)
$$

which can be integrated to obtain:

$$
\mathrm{F}(\mathrm{t})=1-\mathrm{e}^{-\mathrm{ZN}}
$$

assuming $\mathrm{F}(0)=0$ and $\mathrm{Z}$ is a constant. $N_{T}$ is the number of passes through the rotor-stator, or number of turnovers, defined as $Q \cdot t / V$. Therefore, by fitting equation [11] to the experimental data for the increase of fines volume in time during the deagglomeration process, the $\mathrm{Z}$ value can be estimated for a given set of conditions. The above integration assumptions are borne out by the experimental data presented in Section 4.

\section{Background to the Computational Fluid Dynamics (CFD) study}

The investigation included a Computational Fluid Dynamics (CFD) study under selected conditions to assist the interpretation of the relative performance of the three rotorstator designs used. The flow field calculations were modeled using the k- $\varepsilon$ turbulence model with the rotation of rotor simulated using the multiple reference frame model. In the CFD 
modeling, it was assumed that fluid physical properties are constant and they do not change due to particle break up.

Agglomerate break up was modeled using the approach proposed by Baldyga et al. (2008a) This approach takes into account attractive van-der-Waals forces (eq. 3), repulsive forces from DLVO theory (eq. 4) and fractal structure of agglomerates. The hydrodynamic stresses acting on particles (eq. 6 and eq. 7) were calculated from the k- $\varepsilon$ model. The frequency of breakup is given by turbulent eddy frequency. For agglomerated structures smaller than the Kolmogorov microscale, $\lambda_{k}$ :

$$
\lambda_{k}=\frac{v^{3 / 4}}{\varepsilon^{1 / 4}}
$$

this is given by:

$$
\Gamma=C_{b}\left(\frac{\varepsilon}{v}\right)^{1 / 2}
$$

For agglomerates larger than the Kolmogorov microscale breakup frequency is given by:

$$
\Gamma=C_{b} \frac{\varepsilon^{1 / 3}}{L^{2 / 3}}
$$

Population balance equations were solved using the method of moments. Transport equations for moments of particle size distribution were solved using user defined scalar transport model on the frozen flow field.

Three dimensional CFD models were built for three rotor-stator geometries. Hex-hybrid meshes were generated in Gambit v2.4. Typical size of the mesh was in the range of 2.2-3M cells. The flow field was solved in ANSYS Fluent v6.3 (Figure 4). Typical time of the simulation was 4-5 days on 2CPUs and 4GB on RAM. CFD simulations were run only for one passage of agglomerates through rotor-stator system in order to make comparisons between different geometries. The mean size of agglomerates of the initial dispersion was taken as 104 $\mu \mathrm{m}$ for all cases. 


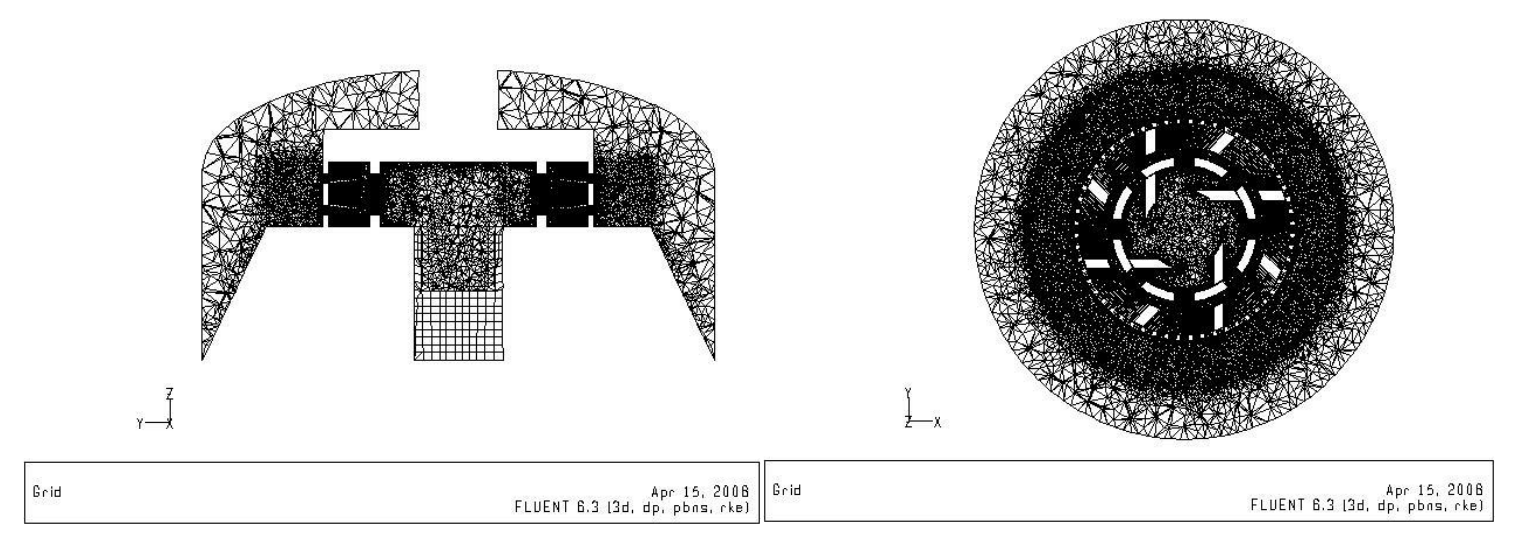

Figure 4. 3D grid for Silverson rotor-stator geometry

\section{RESULTS AND DISCUSSIONS}

\subsection{Mechanism of break up and the finest attainable size}

The evolution of the particle size distribution was observed to be bi-modal during the course of processing for all the rotor-stators, regardless of the operating condition- power input and residence time. As can be seen in Figure 5, which shows a selected set of results for each of the rotor-stator heads, the size and volume of coarse particles gradually decrease whilst the fines remain roughly in the same size range and increase in volume as time progresses. This suggests that the dominant mechanism of break up is erosion where the smallest fragments, aggregates, are chipped off the surface of larger agglomerates (Özcan-Taskin et al, 2009).

We analyse such data in two parts: "fines", or aggregates, which are in the sub-micron range and "coarse" material, i.e. agglomerates, which for this material pair are greater than $1 \mu \mathrm{m}$. The evolution of the Sauter mean diameters for fines and coarse material as well as the whole dispersion is shown in Figure 6 for the same data set in Figure 5.c. It is clear that considering only the mean diameters for the whole dispersion gives the impression that the process is practically complete after about 10 tank turnovers, but in fact, it requires much longer 
to break up all agglomerates as can be seen from the evolution of the coarse material mean sizes.

The Sauter mean diameter for fines is around 150-200 nm. As shown in Figure 7, this does not change in time or depend on the rotor-stator design and operating conditions. These support that aggregates, which are the smallest fragments, are eroded off the surface of agglomerates during processing. 

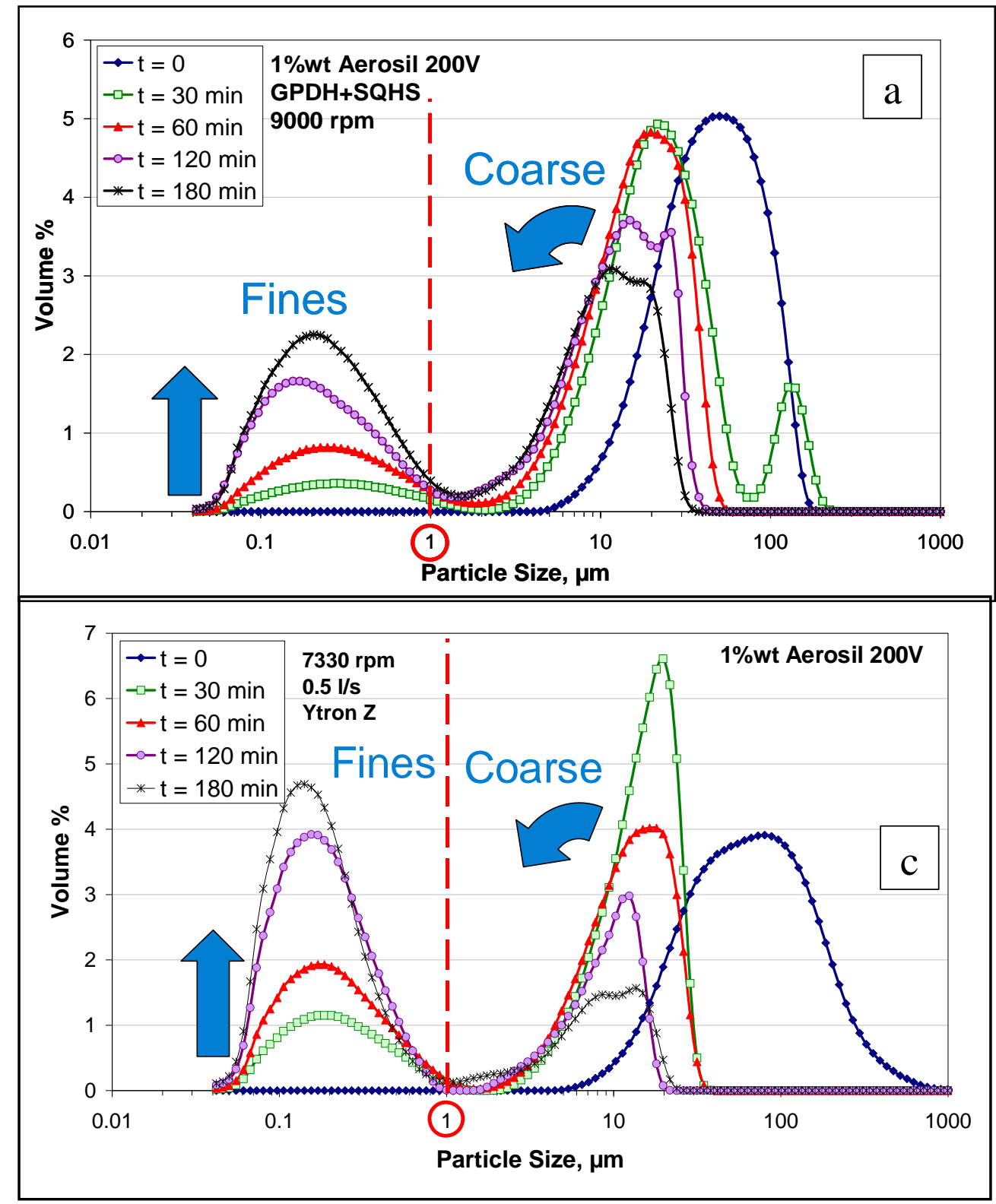

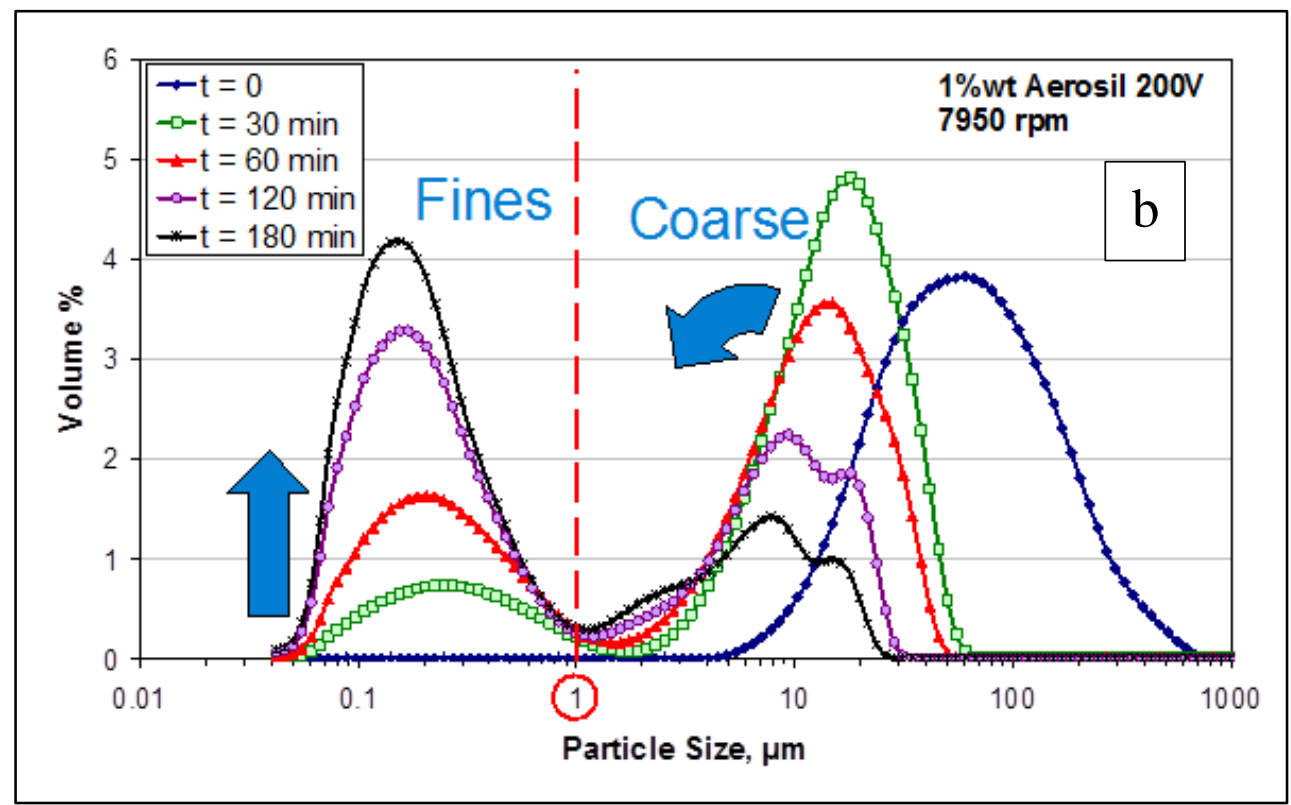

Figure 5 Evolution of PSD during processing with the different rotor-stators used:

(a) GPDH-SQSH operated at 9,000 rpm; 0.6 1/s; (b) EMSC- 7950 rpm, 0.6 1/s; (c) Ytron Z-Lab $7330 \mathrm{rpm}, 0.5 \mathrm{l} / \mathrm{s}$ 


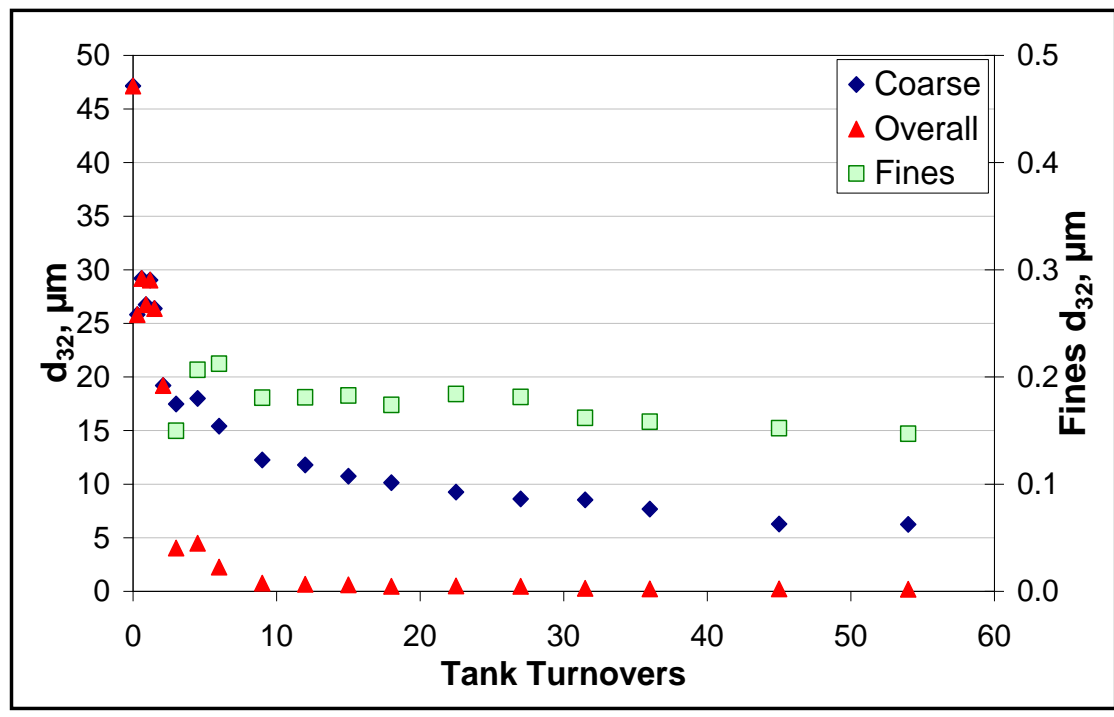

Figure 6 Sauter mean diameters $\left(\mathrm{d}_{32}\right)$ for fines, coarse material and whole dispersion during processing with Ytron Z-Lab at $7330 \mathrm{rpm}$ and $0.5 \mathrm{l} / \mathrm{s}$

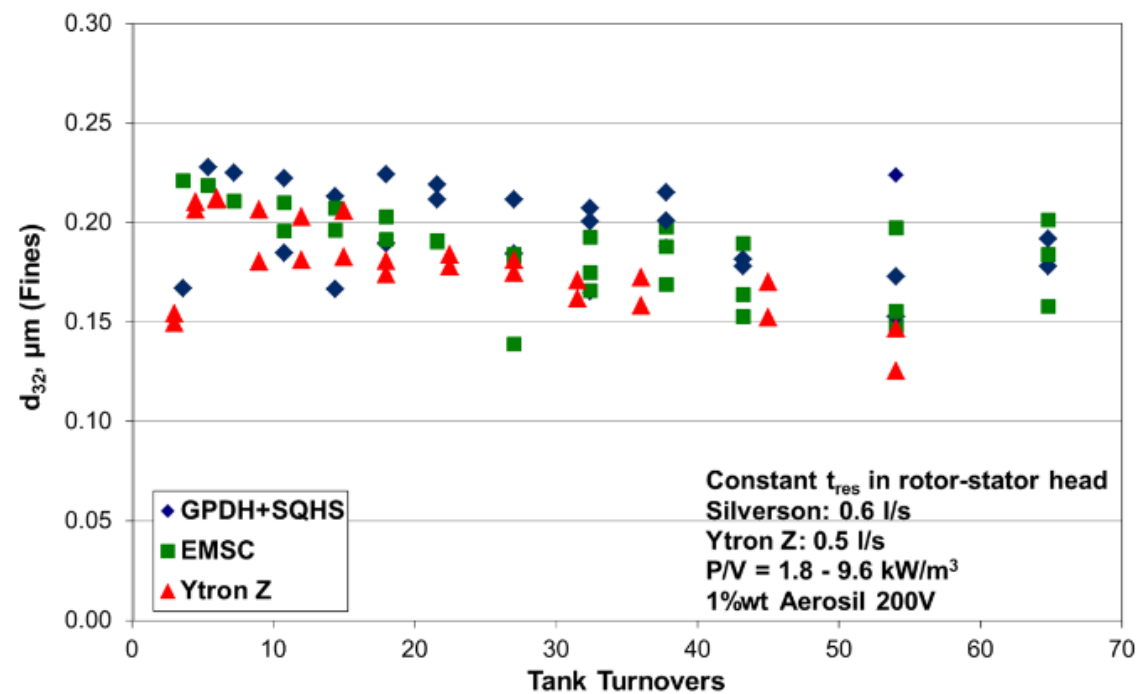

Figure 7 Evolution of $\mathrm{d}_{32}$ of fines during processing with the three rotor-stators obtained over a range of operating conditions

These results relating to both the mechanism of breakup and the smallest attainable size are in line with our previous findings (Bałdyga et al., 2008a; Özcan-Taşkin et al., 2009; Padron et al., 2008) and it may therefore be anticipated that for this test system, breakup will occur through erosion with other rotor-stator designs as well. 


\subsection{Effect of operating conditions on the kinetics of break up}

As breakup occurs through erosion, Sauter mean diameter for coarse material (>1 $\mu \mathrm{m})$ decreases during processing which is shown in Figure 8 for one of the rotor-stators used where data are plotted as a function of energy density at different rotor speeds. Increasing the operating speed, and hence both the average power input as shown in Table 3 and turbulence energy dissipation rate (Özcan-Taşkın et al, 2011), increases the rate of breakup of agglomerates. As a result, breakup kinetics increases (Figure 8). It is worth pointing out that different data sets cannot be pulled together with energy density and hence both the specific power input and processing time need to be considered when evaluating results.

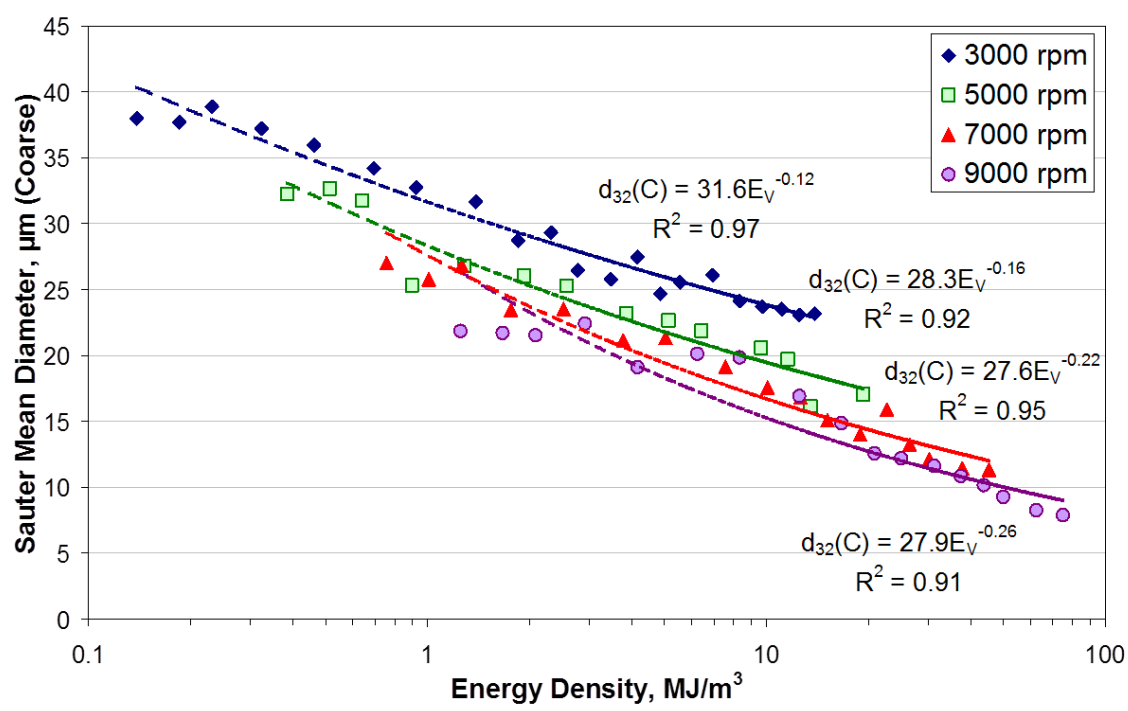

Figure $8 \mathrm{~d}_{32}$ for coarse material with GPDH-SQHS over a range of operating conditions

Data can also be analysed in terms of the evolution of fines generation rate. This is shown in Figure 9 for another rotor-stator geometry, the EMSC. The increase in the fines generation rate with increases in the specific power input can be followed in this Figure where $\mathrm{Z}$ values are also included. 


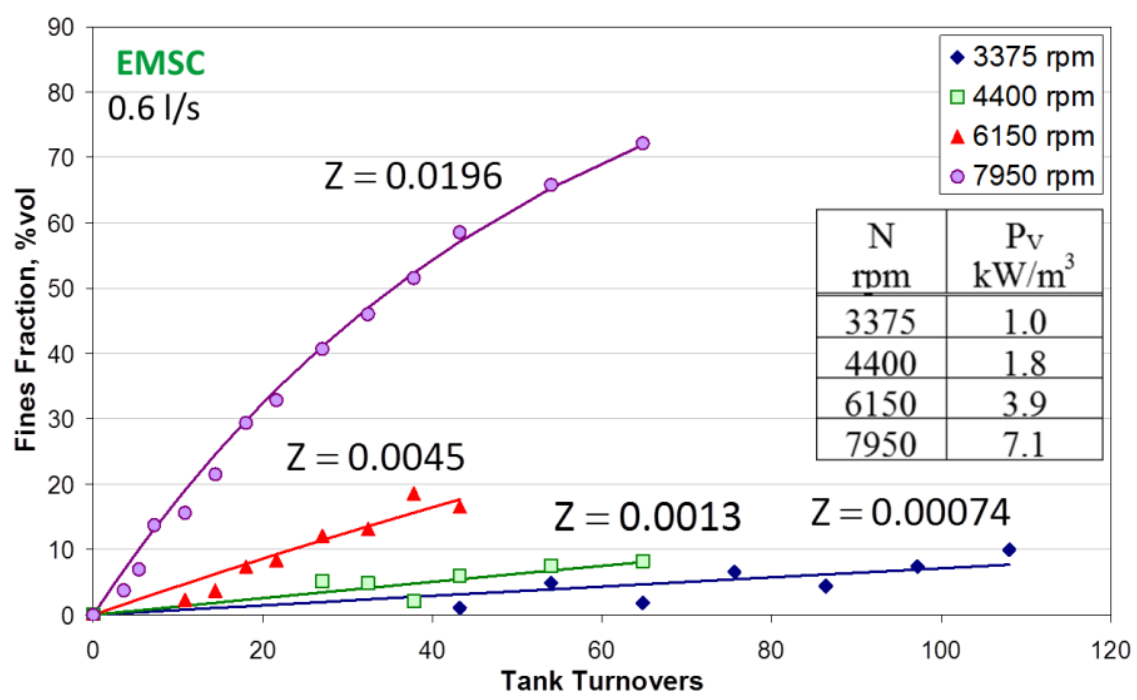

9

Figure 9 Evolution of fines volume fraction using the EMSC

The effect of flow rate was studied with Ytron Z-Lab. Operating at a lower flow rate results in the dispersion having a longer residence time in the mixer head where break up occurs. Consequently, the rate of fines generation per tank turnover is higher at a lower flow rate as shown in Figure 10.a at a comparable power input of around $7.1-7.4 \mathrm{~kW} / \mathrm{m}^{3}$. It is worth bearing in mind that this results in the overall processing time being longer. When the same data set is analysed on the basis of energy density, at a comparable power input, the variation is due to processing time and it is clear that the break up rate is slower for the lower flow rate, as shown in Figure 10.b. Hence, despite the increased breakup rate per tank turnover at lower flow rates, it can be advantageous to operate at a high flow rate to complete the process faster. 


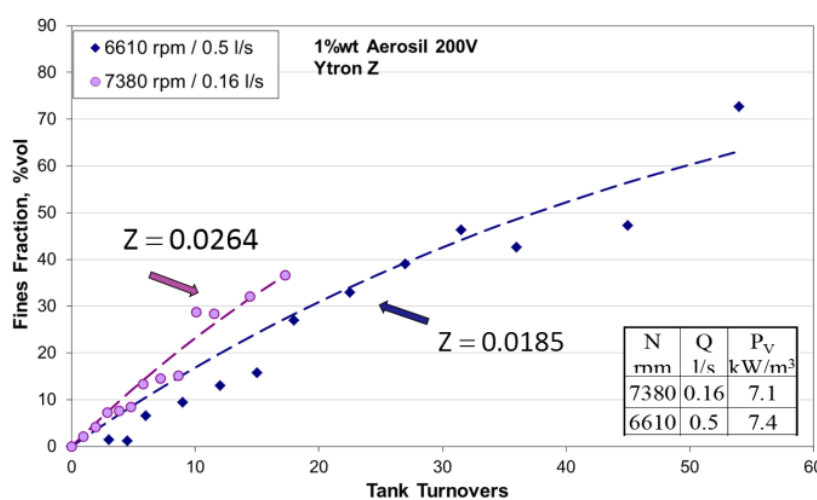

(a)

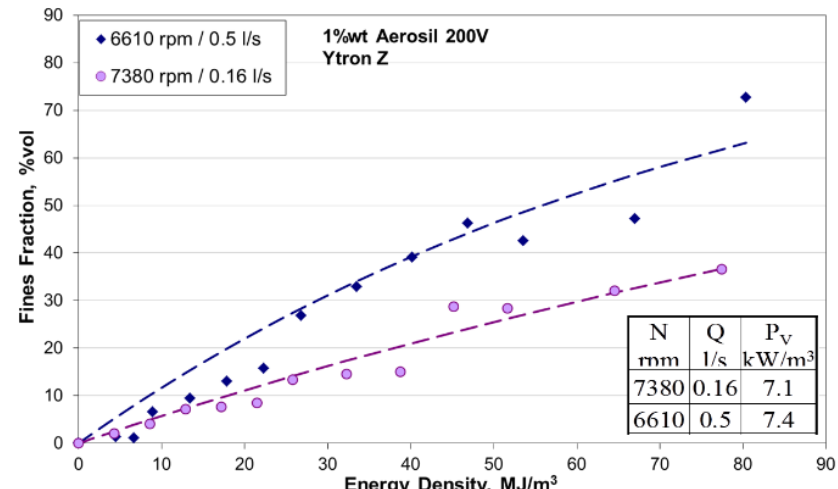

(b)

Figure 10 Effect of flow rate assessed on the basis of (a) tank turn overs and (b) energy density (or processing time as the specific power input values are comparable) on the kinetics of break up

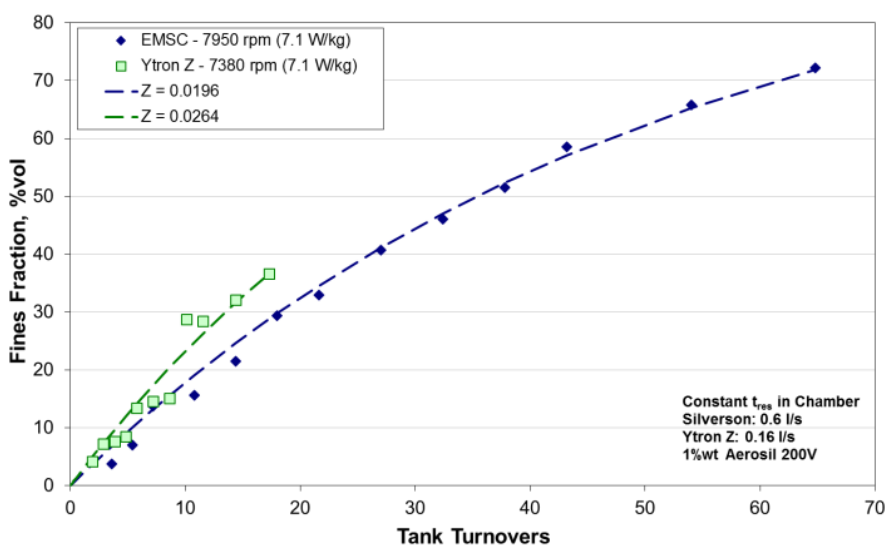

(a)

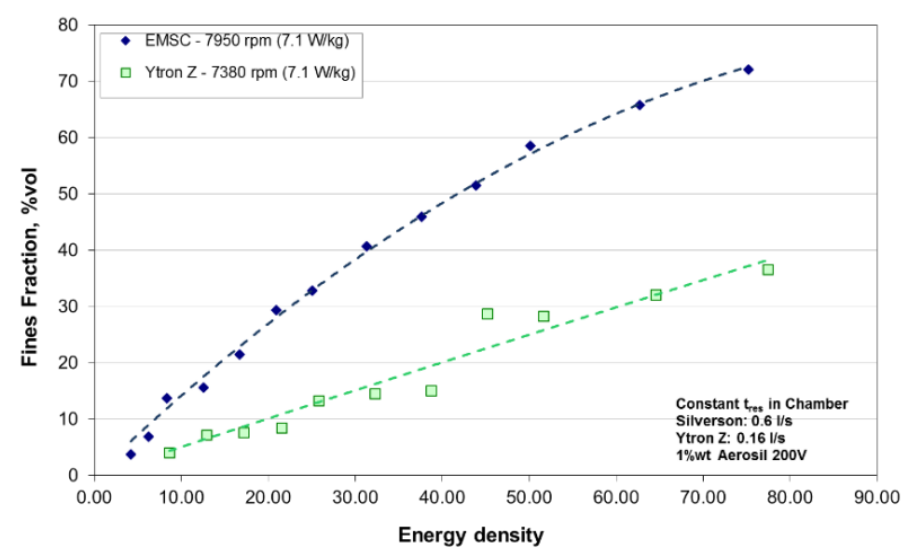

(b)

Figure 11. Comparison of breakup kinetics with EMSC and Ytron Z-Lab at a given power input of $7.1 \mathrm{~W} \mathrm{~kg}^{-1}$ and constant residence time in the chamber on the basis of (a) tank turnovers and (b) energy density 


\subsection{Kinetics of break up with different rotor-stators}

As discussed above, the mechanism of break up and the smallest size that can be attained does not depend on the rotor-stator design or operating conditions but the kinetics of break up does. Different rotor-stator designs are therefore assessed on the basis of kinetics of break up. Comparison of the performance of Silverson 150/250MS and Ytron Z-Lab devices is complicated due to the differences in the volume of both the chamber and rotor-stator head. In addition, as mentioned in Section 2, a smaller range of flow rates was covered with Ytron ZLab, even after the addition of the pumping wheel. The performance of the different devices has been assessed for a given residence time in the mixing chamber or in the rotor-stator head and these are presented on the basis of tank turnovers or energy density.

For a given residence time in the chamber, Ytron Z-Lab had higher $\mathrm{Z}$ values compared to the EMSC at a given average power input. Figure 11.a shows this comparison at an average specific power input of $7.1 \mathrm{~W} \mathrm{~kg}^{-1}$ : over the comparable range of tank turnovers, the $\mathrm{Z}$ value of Ytron $\mathrm{Z}$ is $35 \%$ higher than that for EMSC. This higher $\mathrm{Z}$ value is due to the longer residence time in the rotor-stator head, which in this case was three times higher than that in EMSC: 0.3 s for Ytron Z-Lab compared to $0.1 \mathrm{~s}$ for EMSC (Table 3). On the other hand, if the comparison is made on energy density basis, it can be seen that the EMSC, operating at a higher flow rate, achieves a higher fraction of fines (Figure 11.b).

It was shown in our previously reported work (Özcan-Taşkın et al, 2011) that with the Ytron Z-Lab rotor-stator head, which practically occupies the whole of the mixing chamber, the energy dissipation rate is more uniformly distributed. On the other hand, with EMSC and GPDH-SQSH the zone of high energy dissipation rate is located between the inner rotor and outer screen and within the jets. Therefore, further comparisons of the kinetics of break up at comparable specific power input values were made for comparable residence time values in the rotor-stator head where breakup would be expected to occur. Figure 12 compares the fines 
volume fraction with different rotor-stator heads at comparable residence time values in the rotor-stator head. It can be seen that overall, EMSC has a higher fines generation rate compared to the GPDH-SQSH. This would be due to the differences in the amount of fluid re-entrained into the mixer head as reported by (Özcan-Taşkın et al, 2011).

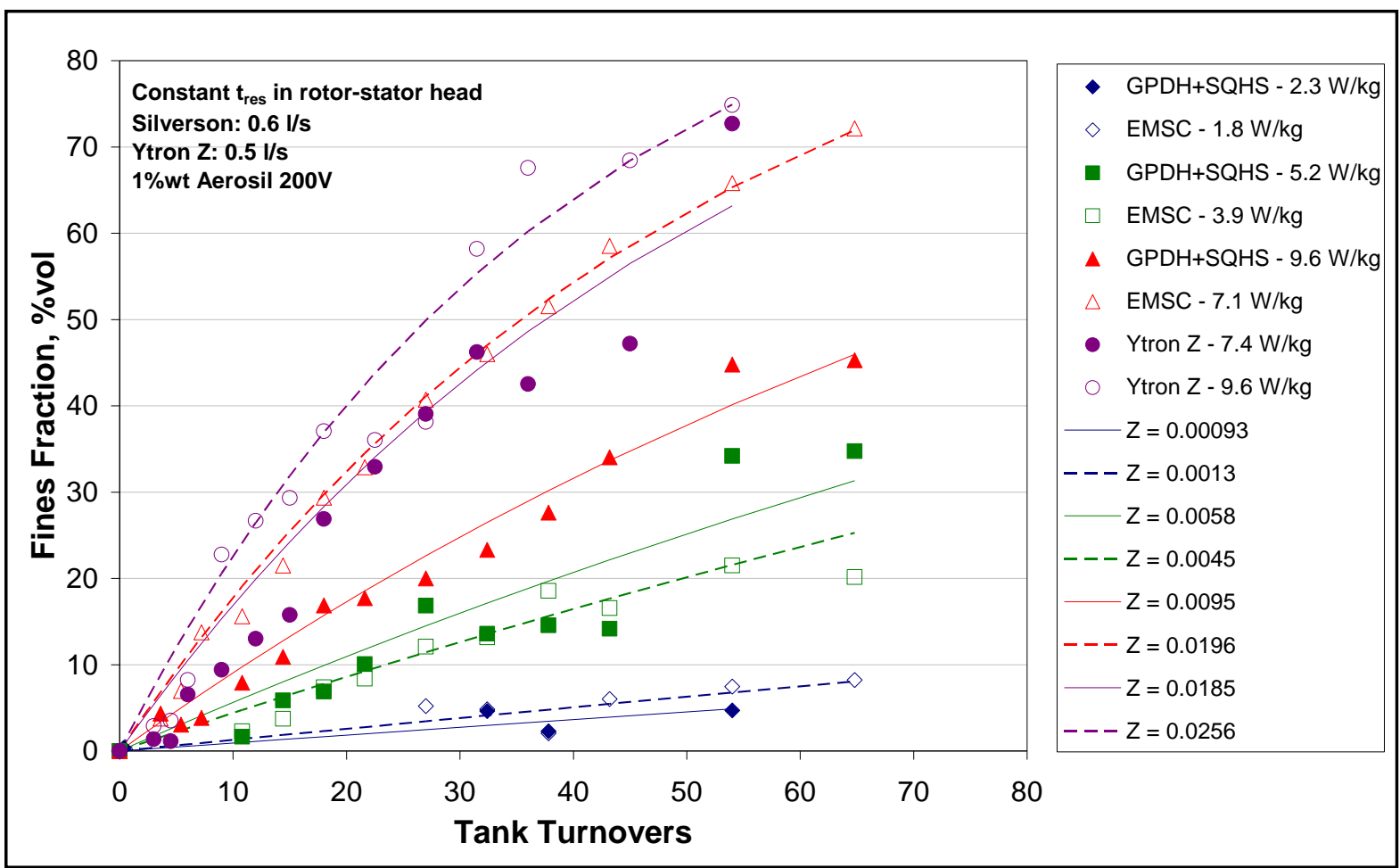

Figure 12 Comparison of fines generation rate with different rotor-stators at a given residence time in the rotor-stator head

CFD results obtained using these two rotor-stator heads are presented in Figure 13 in the form of number concentrations and average agglomerate size in Figure 14. These were for the same residence time in the chamber and mixer head, 1 and $0.1 \mathrm{~s}$ respectively, but with the EMSC operating at a lower specific power input, 7.1 compared to $9.6 \mathrm{~W} \mathrm{~kg}^{-1}$. In line with experimental results shown in Figure 12 for these conditions, the more prominent agglomerate size reduction with the EMSC screen- despite the lower average specific power input, compared to the GPDHSQSH- noted from experimental results, is confirmed by these CFD results. 

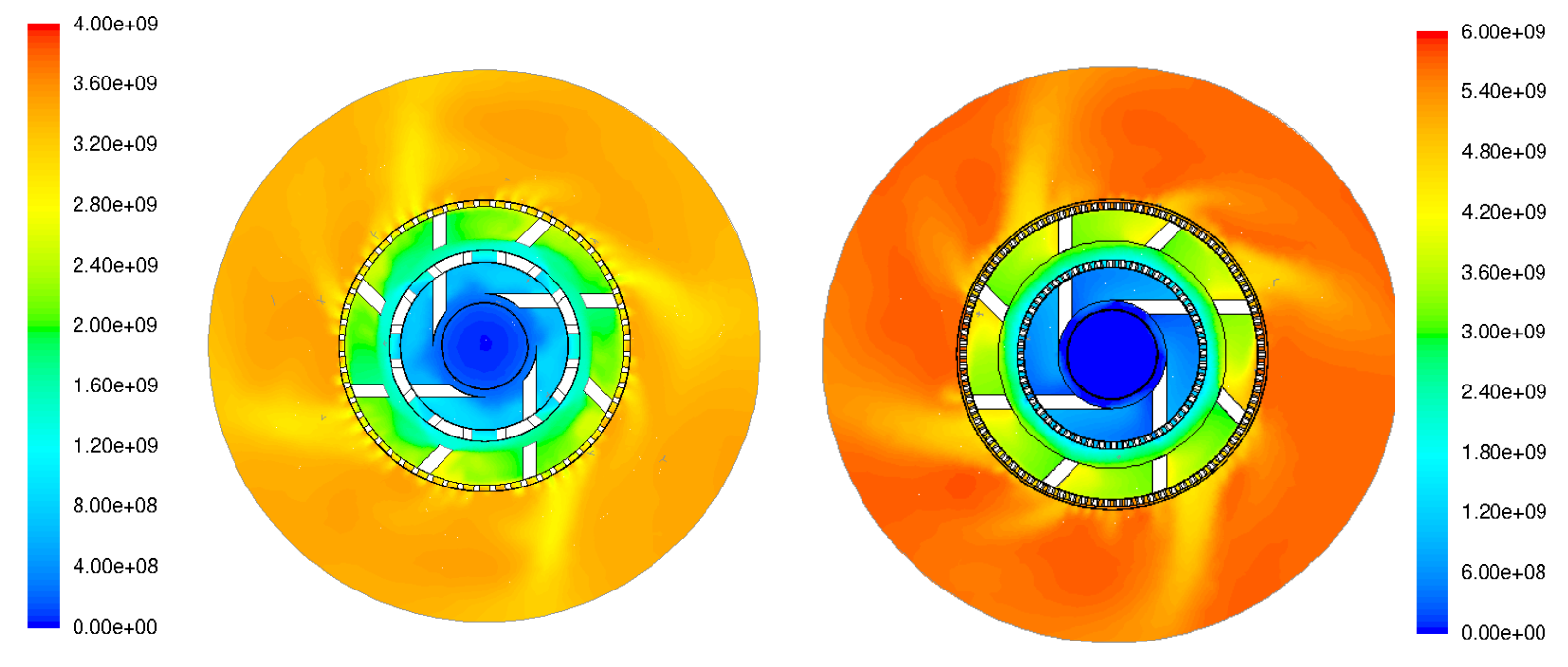

Figure 13 Concentration of number of fines $\left(N_{c}, \mathrm{~m}^{-3}\right)$ using (a) GPDH-SQSH at $9000 \mathrm{rpm}, 0.6 \mathrm{l} / \mathrm{s}, 9.6 \mathrm{~W} \mathrm{~kg}^{-1}$; (b) EMSC at $7950 \mathrm{rpm}, 0.6 \mathrm{l} / \mathrm{s}, 7.1 \mathrm{~W} \mathrm{~kg}^{-1}$

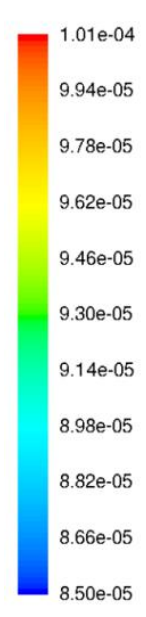

(a)

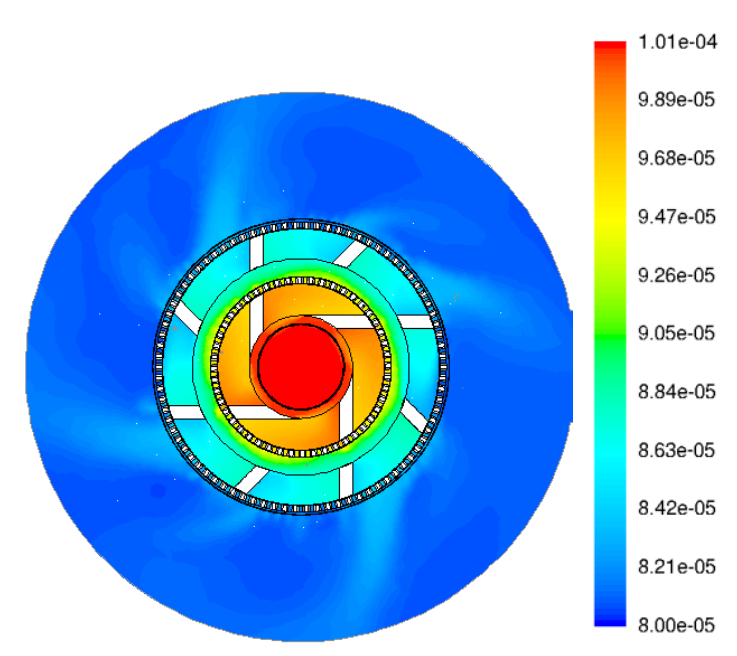

(b)

Figure 14 Average agglomerate size $\left(\mathrm{d}_{30}, \mu \mathrm{m}\right)$ obtained with

(a) GPDH-SQSH at $9000 \mathrm{rpm}, 0.6 \mathrm{l} / \mathrm{s}, 9.6 \mathrm{~kg}^{-1}$ and (b) EMSC at $7950 \mathrm{rpm}, 0.6 \mathrm{l} / \mathrm{s}, 7.1 \mathrm{~W} \mathrm{~kg}^{-1}$

In order to make comparisons clearer, the three geometries are assessed on a one-to-one basis. Under comparable conditions, Ytron Z-Lab significantly outperforms GPDH-SQHS when compared on the basis of either tank turnovers or energy density as shown in Figure 15. CFD results also show that Ytron Z-Lab is more efficient in size reduction of agglomerates (Figure 16). Breakage occurs gradually across the whole chamber as the dispersion passes through the rotor-stator head of Ytron Z-lab, which occupies the chamber, whereas for the GPDH-SQHS all break up takes place in the screens. 

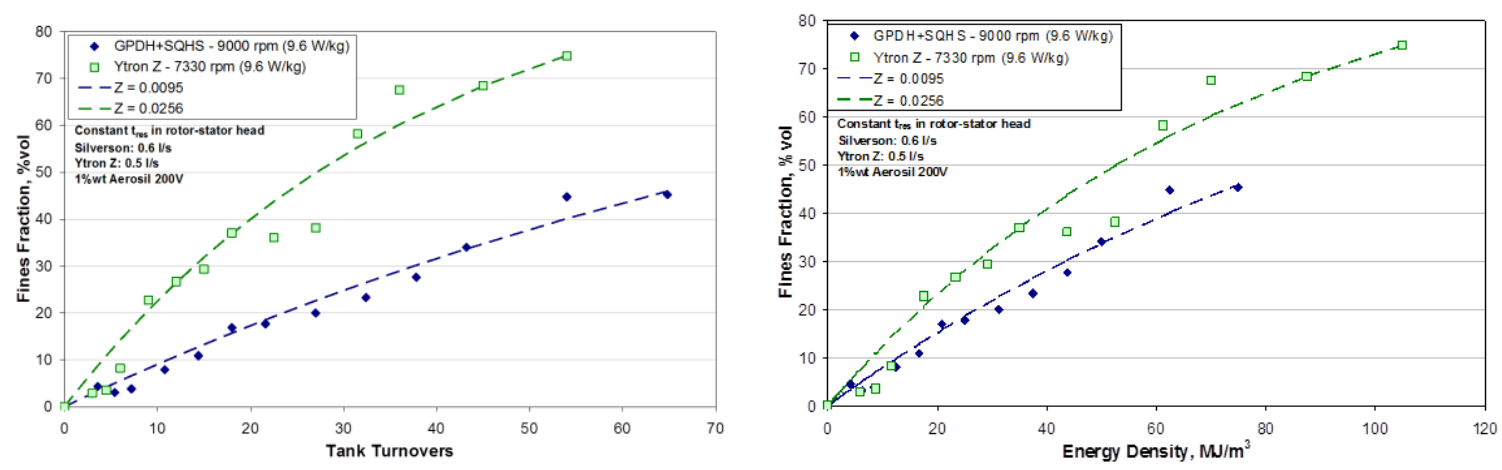

Figure 15 Comparisons of GPDH-SQSH and Ytron Z-Lab rotor-stators at a given specific power input $\left(9.6 \mathrm{~W} \mathrm{~kg}^{-1}\right)$ and residence time in the rotor-stator head $(0.1 \mathrm{~s})$
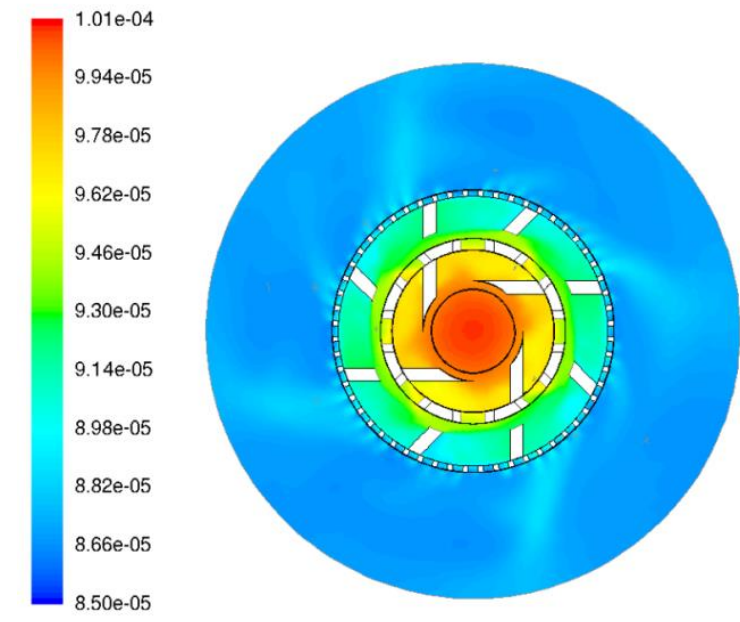

(a)

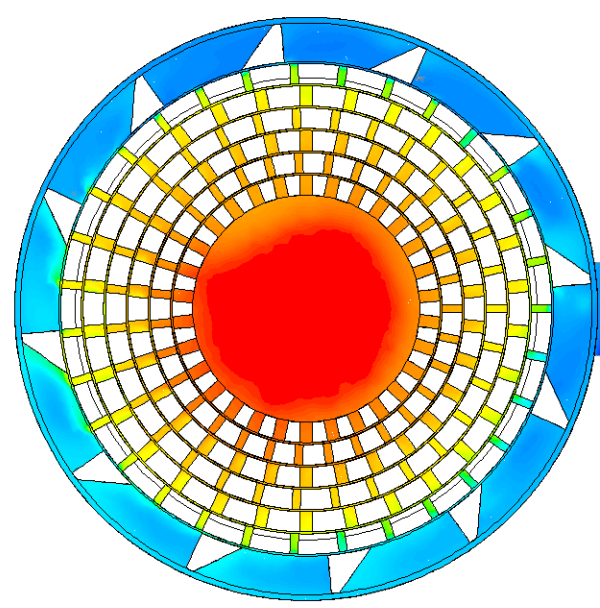

(b)

Figure 16 Average agglomerate size $\left(\mathrm{d}_{30}, \mu \mathrm{m}\right)$ obtained at a given specific power input of $9.6 \mathrm{~W} \mathrm{~kg}^{-1}$ and residence time in rotor-stator head of $0.1 \mathrm{~s}$ using (a) GPDH-SQSH at $9000 \mathrm{rpm}$, $0.61 / \mathrm{s}$, and (b) Ytron Z-Lab at $7330 \mathrm{rpm}, 0.5 \mathrm{l} / \mathrm{s}$

Comparisons of EMSC with Ytron Z-Lab on the basis of tank turnovers shows that fines generation rates at a similar specific power input $(7.1-7.4 \mathrm{~W} / \mathrm{kg})$ and constant residence time in the mixing head for the two designs are comparable (Figure 17.a). The $\mathrm{Z}$ values are within $5-6 \%$ of each other. When these two rotor-stators are compared in terms of energy density, the EMSC appears to have a slightly higher fines volume fraction (Figure 17.b). 

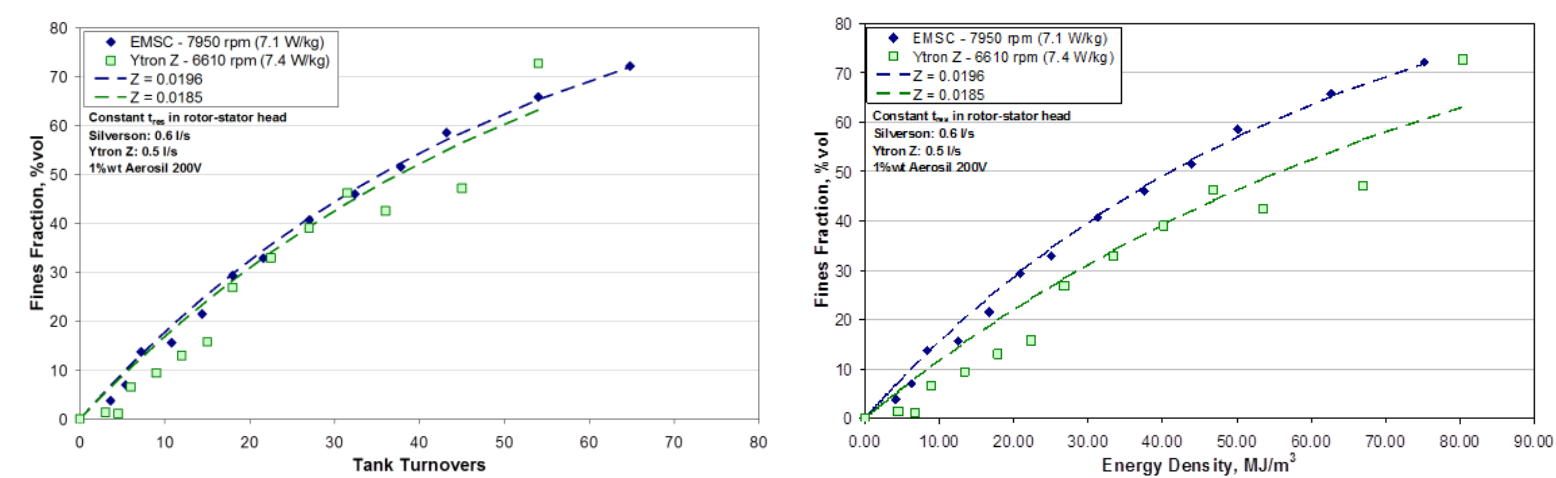

Figure 17 Comparisons of EMSC and Ytron Z-Lab rotor-stators at a comparable specific power input and residence time in the rotor-stator head

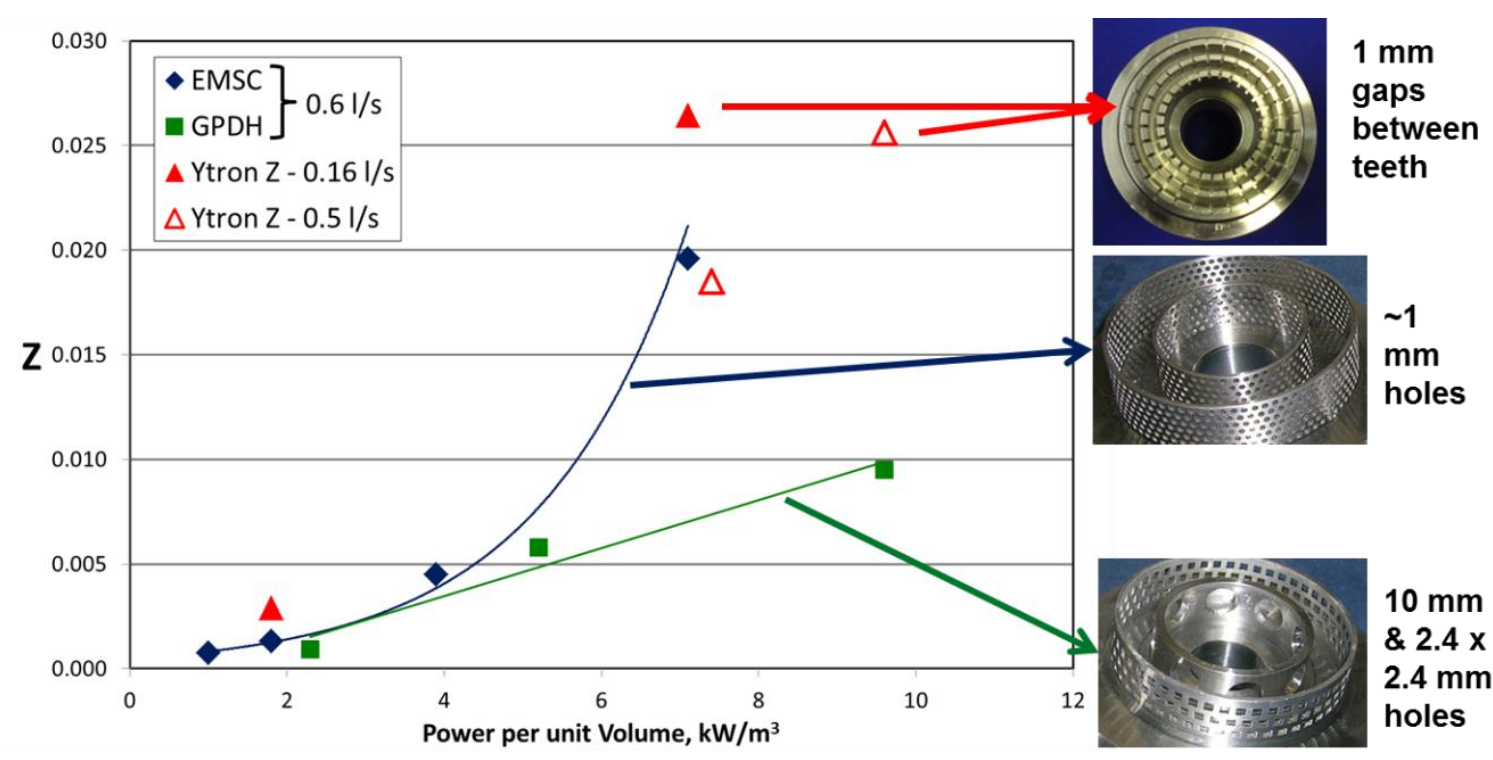

Figure $18 \mathrm{Z}$ values as a function of power input for the three rotor-stator geometries studied

Due to the inherent differences in the design of rotor-stators on the market, it is not possible to make comparisons at a given chamber and mixer head volume whilst maintaining the flow rate the same. Nonetheless, the data obtained have been used make an overall comparison as shown in Figure 18 with the $\mathrm{Z}$ values of the three rotor-stator geometries as a function of average power per unit volume. At low power inputs (less than $\sim 5 \mathrm{~kW} / \mathrm{m}^{3}$ ) the $\mathrm{Z}$ values of the three units are comparable. At higher power inputs the deagglomeration rate $(\mathrm{Z})$ of the GPDHSQHS is significantly lower than the other two. This indicates that geometries with higher number of smaller holes and/or gaps between teeth are more energy efficient achieving a higher deagglomeration rate for a given power input. 


\section{CONCLUSIONS}

Three different rotor-stator designs, namely the GPDH-SQSH and EMSC from Silverson and the Ytron Z-Lab were used to study the breakup of agglomerates of hydrophilic fumed silica particles (Aerosil ${ }^{\circledR} 200 \mathrm{~V}$ ) and determine the smallest attainable size, mechanism and kinetics of breakup.

Over the wide range of power input values covered in the study, 1 to $\sim 10 \mathrm{~W} \mathrm{~kg}^{-1}$, with three different rotor-stator designs, agglomerates of silica particles were found to be broken up through erosion. This resulted in a bi-modal PSD and an increase in the volume of fines (below $1 \mu \mathrm{m}$ ) during processing accompanied by a decrease in both the volume and size of coarse material. This is in agreement with our previous findings using the GPDH-SQSH design operated in a different mode (ramping up the speed, Padron et al, 2008) and findings of previous researchers who used fumed silica particles in other devices (Xie et al, 2007, 2008, Pacek et al, 2007).

The finest size attained with different rotor-stators and under different operating conditions was found to be that of aggregates rather than the primary particles as would be expected with these fumed silica particles which are produced at very high temperatures. This was in the range of 150- $200 \mathrm{~nm}$, regardless of the operating conditions or rotor-stator design.

Whilst the mechanism of break up or the smallest attainable size did not depend on the operating conditions, it could be shown that the kinetics of break up depends on the operating conditions and rotor-stator design chosen. Fines generation rate and the rate of size reduction of coarse particles increased with increasing rotor speed, hence increasing specific power input, or energy density. Energy density did not correlate the data and for a given rotor-stator design 
operated at a given flow rate, i.e. residence time, the rate of fines generation compared on the basis of energy density was different for different specific power input values.

With a given rotor-stator operated at a given power input, the fines generated per tank turnover increased as the flow rate was reduced which is due to the increase of the residence time of the dispersion in the high energy dissipation zone. This however, resulted in an overall longer processing time and increasing the flow rates resulted in an increase in fines volume fraction at a given time during processing.

The differences in the volume of the mixing chamber and rotor-stator head for the Silverson and Ytron devices meant that comparisons had to be made at different flow rates to match the residence time in the mixer head and rotor-stator head. Comparisons made at a given power input and residence time in the mixing chamber showed that the kinetics of break up per tank turnover is much higher with Ytron Z-Lab, which operates at a lower flow rate, than the EMSC. On the other hand, on energy density basis a higher fraction of fines is achieved with the EMSC, which means that the processing time with this head, which operates at a higher flow rate to match the residence time, is shorter.

Further comparisons at comparable power input values were made at flow rates to match the residence time in the rotor-stator head as the highest levels of energy dissipation rate occurs in these zones. EMSC geometry in most cases had a higher fines generation rate than the GPDH-SQHS; at worst the two were comparable. This would be due to differences in the amount of fluid re-entrained into the mixing, which increases the effective residence time of some of the agglomerates in the high energy dissipation zone, resulting in a higher fines generation rate at a comparable power input value. It was not possible to cover the same flow rate range as with Silverson 150/250 as with Ytron Z-Lab, to make comparisons over a range of conditions. Based on the amount of comparable data, Ytron Z-Lab also seems to be an efficient design for break up. This is consistent with the results of our CFD studies which 
showed that the energy dissipation rate is more homogenously distributed throughout the mixer head of Ytron Z-Lab. It outperformed GPDH-SQSH when compared on the basis of tank turnovers or energy density. When compared with the EMSC, the rate of break up was found to be higher per tank turnover as Ytron Z-Lab is operated at a lower flow rate resulting in longer residence times in the mixer head. EMSC on the other hand had a higher rate of break up on the basis of energy density, which means that the process time would be shorter. Results from a brief CFD study performed under selected conditions were in agreement with experimental data.

An overall comparison has shown that the high number and small size of holes in the mixer head of a rotor-stator would enhance the performance of an in-line rotor-stator in breaking up agglomerates.

\section{ACKNOWLEDGEMENTS}

The authors gratefully acknowledge the members of the DOMINO consortium for technical discussions, directions and financial support as well as consultants, Prof. J. Baldyga of Warsaw University of Technology and Dr A.W. Etchells. 


\section{NOMENCLATURE}

C Off-bottom clearance of the impeller $\mathrm{m}$

D Impeller or rotor diameter $\quad \mathrm{m}$

$d_{32} \quad$ Sauter mean diameter (area-weighted average particle size) $\quad \mu \mathrm{m}$

$\begin{array}{lll}e & \text { Electron charge } & \mathrm{C}\end{array}$

F $\quad$ Fines volume fraction

$\begin{array}{lll}F_{T} \quad \text { Interaction forces acting on agglomerates } & \mathrm{N}\end{array}$

$\begin{array}{lll}F_{A} \quad \text { Attractive forces acting on agglomerates } & \mathrm{N}\end{array}$

$F_{R} \quad$ Repulsive forces acting on agglomerates $\quad \mathrm{N}$

$H \quad$ Surface to surface distance m

$\mathrm{Ha}$ Hamaker constant

$\begin{array}{lll}k_{b} & \text { Boltzman constant } & \mathrm{J} \mathrm{K}^{-1}\end{array}$

$l \quad$ Macroscale of turbulence $\quad \mathrm{m}$

La Aggregate size m

$L_{i} \quad$ Agglomerate size $\mathrm{m}$

$N \quad$ Impeller or rotor speed $\quad \mathrm{s}^{-1}$

$N_{c} \quad$ Number concentration of particles $\quad \mathrm{m}^{-3}$

$N_{T} \quad$ Number of tank turnovers

$P \quad$ Power input W

$\mathrm{Po}_{1} \quad$ Rotor-stator power number 1

$\mathrm{Po}_{2} \quad$ Rotor-stator power number 2

$Q \quad$ Volumetric flow rate $\quad \mathrm{m}^{3} \mathrm{~s}^{-1}$

$q_{1} \quad$ Particle size distribution function at the rotor-stator inlet

$q_{2} \quad$ Particle size distribution function at the rotor-stator outlet

$q_{c} \quad$ Coarse particle size distribution function

$q_{f} \quad$ Fines particle size distribution function 
$R \quad$ Particle radius

$T \quad$ Tank diameter $\mathrm{m}$

$\begin{array}{lll}T & \text { Temperature in eqn } 4 & \mathrm{~K}\end{array}$

$t_{\text {res }}{ }^{C} \quad$ Residence time in the rotor-stator chamber $\quad \mathrm{s}$

$t_{r e s}{ }^{M H}$ Residence time in the rotor-stator mixing head $\mathrm{s}$

$V \quad$ Volume of dispersion $\quad \mathrm{m}^{3}$

$V_{C} \quad$ Volume of the rotor-stator mixing chamber $\quad \mathrm{m}^{3}$

$V_{M H} \quad$ Volume of the rotor-stator mixing head $\mathrm{m}^{3}$

$V_{\text {Tank }}$ Volume of dispersion in the tank $\mathrm{m}^{3}$

z Valence of ions

Z Fines volume fraction generated in a single pass through the rotor-stator -

\section{Greek}

$\Gamma \quad$ Breakup frequency $\quad \mathrm{s}^{-1}$

$\begin{array}{lll}\lambda_{k} & \text { Kolmogorov microscale } & \mathrm{m}\end{array}$

$\varepsilon_{a} \quad$ Porosity of nanoparticle clusters

$\begin{array}{lll}\sigma_{T} & \text { Tensile strength of agglomerates } & \mathrm{Pa}\end{array}$

$\kappa \quad$ Reciprocal of the double layer thickness $\quad \mathrm{m}^{-1}$

$\psi_{0} \quad$ Surface potential due to the surface charge on the particle V

$\varepsilon \quad$ Local energy dissipation rate per unit mass of liquid $\quad \mathrm{m}^{2} \mathrm{~s}^{-3}$

$\bar{\varepsilon} \quad$ Average volume fraction of aggregates

$\chi \quad$ Static permittivity

$\tau \quad$ Turbulence stresses acting on agglomerates $\quad \mathrm{Pa}$

$\rho \quad$ Dispersion density $\quad \mathrm{kg} \mathrm{m}^{-3}$

$v \quad$ Kinematic viscosity $\quad \mathrm{m}^{2} \mathrm{~s}^{-1}$ 

Abbreviations
CFD Computational Fluid Dynamics
PBT Pitched Blade Turbine
PSD Particle Size Distribution

\section{REFERENCES}

Bałdyga, J., Bourne, J. R. (1994) "Drop breakup in the viscous subrange: a source of possible confusion" Chem. Eng. Sci., 49, p:1077- 1078.

Bałdyga, J., Orciuch, W., Makowski, Ł., Malik, K., Özcan-Taşkin, G., Eagles, W., \& Padron, G. (2006) Baldyga, J.; Orciuch, W.; Makowski, L.; Özcan-Taşkin N. G.; Eagles, W. (2006) "Break up of nanoparticle clusters using an in-line rotor-stator- CFD results" AIChE Meeting11- 15 November 2006, San Francisco, USA.

Baldyga J.; Orciuch W.; Makowski L.; Ozcan-Taskin G.; Eagles W.; Padron G. (2007a) “Break up of nanoparticle agglomerates in a rotor-stator device” Inzynieria Materialowa, 3-4, p: 236- 241.

Baldyga J.; Orciuch W.; Makowski L.; Ozcan-Taskin G.; Eagles W.; Padron G. (2007b) “Break up of nanoparticle agglomerates in a rotor-stator device" 18th Physical Metallurgy and Material Science Conference- Advanced Materials and Technologies, 18- 21 June 2007, Warsaw Poland.

Bałdyga, J., Orciuch, W., Makowski, Ł., Malik, K., Özcan-Taşkin, G., Eagles, W., \& Padron, G. (2008a) "Dispersion of Nanoparticle Clusters in a Rotor-Stator Mixer" Industrial \& Engineering Chemistry Research, 47(10), 3652-3663. doi:10.1021/ie070899u

Bałdyga, J., Orciuch, W., Makowski, Ł., Malski-Brodzicki, M., Malik, K. (2008b) " Break-Up of nanoparticle clusters- process modeling" Journal of Dispersion Science and Technology, 2008, Vol.29(4), p.555-563, doi: 10.1080/01932690701729120. 
Bałdyga, J., Makowski, Ł., Orciuch, W., Sauter, C., Schuchman, H.P. (2009) "Agglomerate dispersion in cavitating flows" Chemical Engineering Research and Design, 2009, Vol.87(4), pp.474- 484 doi:10.1016/j.cherd.2008.12.015

Barthel (1995) "Surface interactions of dimethylsiloxy group-modified fumed silica" Colloids and Surfaces A: Physicochemical and Engineering Aspects Volume 101, Issues 2-3, 30 August 1995, Pages 217-226 http://dx.doi.org/10.1016/0927-7757(95)03179-H

Ferch, H. K. (2005) "Industrial synthetic silicas in powder form" in Colloidal Silica: Fundamentals and Applications Editors Bergna, H.E.; Roberts, W.O.

Hinze, J.O. (1955) "Fundamentals of the Hydrodynamic Mechanism of Splitting in Dispersion Processes" AIChE Journal, Vol.1, No 3, p: 289- 295.

Kammler, H.K.; Madler, L. ; Pratsinis S.E. (2001) "Flame synthesis of nanoparticles" Chem. Eng. Technol., 24, 6, 584- 596.

Kolmogorov, A.N. (1949) “The breakup of droplets in a turbulent stream Dokl. Akad. Nauk. $66,825-828$

Kowalski, A. J., Watson, S., \& Wall, K. (2008) "Dispersion of nanoparticle clusters by ball milling” Journal of Dispersion Science and Technology, Vol 29 (4). 600-604, (doi:10.1080/01932690701729609).

Özcan-Taşkin, N. G., Padron, G., \& Voelkel, A. (2009). Effect of particle type on the mechanisms of break up of nanoscale particle clusters. Chemical Engineering Research and Design, 87(4), 468-473. doi:10.1016/j.cherd.2008.12.012

Özcan-Taşkın, G., Kubicki, D., \& Padron, G. A. (2010). Power and flow characteristics of three rotor-stator heads. NAMF 2010, Victoria Island, Canada.

Özcan-Taşkın, G., Kubicki, D., \& Padron, G. A. (2011). Power and flow characteristics of three rotor-stator heads. The Canadian Journal of Chemical Engineering, 89(5), 1005-1017. doi:10.1002/cjce.20553 
Pacek, A.W., Ding, P., Utomo, A.T. (2007) "Effect of energy density, pH and temperature on de-aggregation in nano-partciles/water suspensions in high shear mixer" Powder Technology, 173, p: 203-210 doi:10/1016/j.powtec.2007.01.006.

Padron, G., Eagles, W. P., Özcan-Taşkin, G. N., McLeod, G., \& Xie, L. (2008). Effect of Particle Properties on the Break Up of Nanoparticle Clusters Using an In-Line RotorStator. Journal of Dispersion Science and Technology, 29(4), 580-586. doi:10.1080/01932690701729237

Rumpf, H. (1962) The strength of granules and agglomerate, in Agglomeration (Editor W. A. Knepper, Interscience, New York, p: 379- 418.

Sauter, C.; Pohl, M., Schuchmann, H.P. (2006) "Ultrasound for disoersing nanoparticles" $12^{\text {th }}$ European Conference on Mixing, 27-30 June, Bologna, Italy.

Sauter, C.; Emin, M.A., Schuchmann, H.P., Tavman, S. (2008) " Influence of hydrostatic pressure and sound amplitude on the ultrasound induced dispersion and de-agglomeration of nanoparticles" Ultrasonics sonochemistry Vol 15, Issue 4, p: 517- 523 doi:10.1016/j.ultsonch.2007.08.010.

Sauter, C.; Schuchmann, H.P. (2012) "High pressure for dispersing and de-agglomerating nanoparticles in aqueous solutions" Chemical Engineering \& Technology, 2007, Vol.30(10), pp.1401-1405 doi: 10.1002/ceat.200700115

Schilde, C., Beinert, S., Kwade, A. (2011) "Comparison of the micromechanical aggregate properties of nanostructured aggregates with the stress conditions during stirred media milling" Chem. Eng. Sci, 66, p: 4943- 4952 doi: 10.1016/j.ces.2011.07.006.

Shaw, D.J. (1992)"Introduction to colloid and surface chemistry" Butterworths, London, p:211243

Tang, S.; Ma, Y.; Shui, C. (2001) "Modelling the mechanical strength of fractal aggregates" Colloids and Surfaces A: Physicochem Eng Aspects, 180; 7- 16. 
Ulrich, G. D., and Riehl, J. W. (1982) Aggregation and growth of sub-micron sized oxide particles in flames. J of Colloid Interface Sci. 87:257-265.

Xie, L., Rielly, C.D., Eagles, W., Özcan-Taşkin, N. G. (2007) "Dispersion of nanoparticle clusters using mixed flow and high shear impellers in stirred tanks" Trans. IChemE, Vol 85 (A5), p: 676- 684 doi: 10.1205/cherd06195.

Xie, L., Rielly, C.D., Özcan-Taşkin, N. G. (2008) "Breakup of nanoparticle agglomerates by hydrodnamically limited processes" Jrnl of Disp. Sci. and Tech., 29 (4), p: 573- 569 doi:10/1080/01932690701729211.

Zhang, J.; Xue, X. and Li W. (2012) High shear mixers: a review of typical applications and studies on power draw, flow pattern, energy dissipation and transfer properties" Chem. Eng. and Proc., 57-58, p: 25- 41 doi.org/10.1010/j.cep.2012.04.004. 